\title{
Comparing Different Methods Used for Prevention of T-Junction Dehisence in Wise Pattern Reduction Mammoplasty
}

\author{
AHMED R. MORSI, M.D.; DINA BADAWI, M.D., M.R.C.S.; HAYTHAM A.A. ALMALAHY, M.Sc.; \\ ASHRAF EL-SEBAIE, M.D. and TAREK MAHBOUB, M.D. \\ The Department of Plastic Surgery, Faculty of Medicine, Cairo University, Egypt
}

\begin{abstract}
Introduction: The female breast is regarded as a symbol of femininity. The aesthetically pleasing breast will be of a size proportional to the body, be tear drop to conical in shape, and have the nipple positioned at the anterior most position. Deviations from normal size, shape, and symmetry are interpreted as unattractive. Wise pattern reduction mammoplasty is commonly used procedure for aesthetic and functional purposes. The use of the superomedial pedicle has increased over the past decade, as it has many reported benefits. The combination of the superomedial pedicle with the traditional Wise-pattern skin resection has gained increasing popularity for its versatility and ability to achieve significant aesthetic results. Wound problem complications remain relatively common, as well as the tendency of the outcome to deteriorate in some cases, with loss of projection and bottoming out of the lower breast pole. T-junction necrosis and infection are the most common complications encountered. The aim of this work is to compare between 2 modifications of Wise pattern technique for reducing T-junction dehiscence involving marking and incising an inverted V flap Along the Inframammary fold at the breast meridian and triangular lipodermal flap and finally to select the one of either technique to get the best results.
\end{abstract}

Methods: This is a Prospective randomized comparative study including 30 female patients all complaining of breast hypertrophy and seeking reduction mammaplasty. The patients are divided randomly using a close envelope randomization method into 2 groups. Group (A) will include 15 patients to undergo Wise pattern reduction mammoplasty with inverted V flap. Group (B) will include 15 patients to undergo Wise pattern reduction mammoplasty with triangular lipodermal flap at the caudal end of the breast pillars.

Follow-up is scheduled at the end of the first, second, and fourth postoperative weeks and checking the $\mathrm{T}$ junction for occurrence of dehiscence or not and assessing the degree of dehiscence. Patient satisfaction questionnaire then was presented to the patients.

Results: The rate of major and minimal wound dehiscence was lesser in triangular lipodermal flap than in inverted $\mathrm{V}$ flap though statistically insignificant. Wound healing complications increased with increased BMI of the patients.

Moreover, most of the patients were satisfied by overall outcomes with satisfaction rate of $93.3 \%$ in triangular lipodermal flap and $83.3 \%$ in inverted V flap.
Conclusion: The triangular lipodermal flap could be the future preferred technique as a modification to Wise pattern reduction mammoplasty for prevention or reduce the incidence of $\mathrm{T}$ junction complications.

Key Words: T-Junction - Dehisence - Mammoplasty.

\section{INTRODUCTION}

Wise pattern reduction mammoplasty is a commonly used procedure for aesthetic and functional purposes. The technique gives satisfactory cutaneous reduction in both the transverse and vertical aspects, but in the expense of unavoidable lengthier scar with the possible risk of skin necrosis at the $\mathrm{T}$ - junction [1].

Regarding the superomedial pedicle, which benefits from the versatile blood supply by the perforators branching of the internal mammary artery, the technique has gained popularity in the past decades. Surgeons reported reproducible breast shape, improved superomedial fullness, low rates of nipple loss, and relatively short operating time [2].

As for combining the Wise-pattern skin resection with the superomedial pedicle, this technique proved to be reproducible and satisfactory regarding the amount that can be excised from both the skin envelope and the breast parenchyma [3].

However, wound problem complications remain relatively common (T-junction necrosis and infection are the most common complications encountered). Also, lack of longevity of aesthetic outcomes still occurs, mostly presenting as loss of projection and bottoming out of the lower breast pole [1]. This work aims to compare between two additions to the Wise pattern technique for reducing T-junction dehiscence. These additions involve either marking and incising an inverted $\mathrm{V}$ flap along the inframam- 
mary fold at the breast meridian or a triangular lipodermal flap at the caudal end of the breast pillars. Thereafter, to recognize which one of the two techniques gives the best results.

\section{PATIENTS AND METHODS}

This study was conducted at Kasr Al-Aini Hospital Department of Plastic and Reconstructive Surgery during the period between January 2019 through July 2019.

This is a Prospective randomized comparative study including 30 female patients all complaining of breast hypertrophy and seeking reduction mammaplasty. The patients are divided randomly using a close envelope randomization method into 2 groups. Group (A) will include 15 patients to undergo Wise pattern reduction mammoplasty with inverted V flap. Group (B) will include 15 patients to undergo Wise pattern reduction mammoplasty with triangular lipodermal flap at the caudal end of the breast pillars.

\section{Inclusion criteria:}

1- All patients presented for reduction mammoplasty with Suprasternal notch-Nipple distance $27-35 \mathrm{~cm}$

2- Patients with $\mathrm{BMI} \leq 35 \mathrm{~kg} / \mathrm{m}^{2}$.

\section{Exclusion criteria:}

1- Patients with Suprasternal notch-Nipple distance $\leq 27 \mathrm{~cm}$ or $>35 \mathrm{~cm}$.

2- Patients with comorbidity as uncontrolled diabetes mellitus, uncontrolled cardiovascular conditions, and collagen disorders.

3- Smokers.

4- Patients with active intertrigo and pyoderma gangrenosum.

5- Breast lesions.

\section{Preoperative assessment:}

- Proper history taking and analysis of the complaint.

- Physical examination of the breast and the patient in general.

- Detailed counseling regarding the procedure, the location and the expected length of the scars and informed consent obtained.

- Preoperative sonomammography.

- Preoperative photos to be taken and reviewed with the patients.

Preoperative marking: Wise pattern design

- New nipple position is marked (The Pitanguy point) [3].
- Superomedial pedicle designed (extending from the keyhole pattern to the bottom end of the medial vertical limb. The base extends partially in the keyhole and completely in the vertical limb, leaving $1-2 \mathrm{~cm}$ border around the areola. The width $8-10 \mathrm{~cm}$ ).

- New IMF marked again when the patient is in supine position.

Marking of inverted V flap: (Fig. 1A)

After marking of Wise pattern and new IMF an inverted "V" was additionally marked, centered at the breast meridian, it is an equilateral triangle with each limb measured $2 \mathrm{~cm}$.

Marking of triangular lipodermal flaps: (Fig. 1B):

Standardized Wise pattern marking was done, subsequently at the caudal end of each breast pillars, a triangular zone was marked denoting the future site of triangular lipodermal flaps. These two designed triangles, each measuring $2-3 \mathrm{~cm}$ depending on breast size.

\section{Surgical technique:}

The operative technique of Wise pattern reduction mammoplasty was carried out in the classical fashion as described by Brown [3] and superomedial pedicle as described by Orlando \& Guthrie [4].

\section{Technique of inverted V flap: (Fig. 2)}

Reduction mammoplasty was carried out in standard fashion, and the inverted "V" flap centered on the breast meridian with its base situated in IMF, approximately $4 \mathrm{~cm}$ in the base and with 4 $\mathrm{cm}$ limbs incised slanting towards the pectoralis major fascia.

\section{Techniques of Triangular lipodermal flaps:} (Figs. 3,4)

The 2 designed triangles, each measuring 2-3 $\mathrm{cm}$ depending on breast size, were deepithelialized and incised at their margins, leaving its base in continuity with the corresponding breast pillar. Subsequently, each triangle was dissected from the underlying breast parenchyma with the same thickness of skin flaps, being thicker toward the base to ensure good vascularization. At this stage, attention was devoted to remove most of the unnecessary fat to avoid future fat necrosis. Subsequently the configuration of the new breast mound was achieved by suturing the medial and lateral pillars together, which substantially approximated the two lipodermal flaps making a larger triangle. Then the 2 flaps were sutured together. The new apex then sutured to the musculoaponeurotic layer of the inframammary fold at the breast meridian 
$1 \mathrm{~cm}$ below the inframammary fold. This enables the transfer of most of the tension to the deeper plane rather than the cutaneous plane, providing a tension free zone at the cutaneous $\mathrm{T}$ junction. Care should be taken in order not to induce tethering of the skin edges at the $\mathrm{T}$ junction.

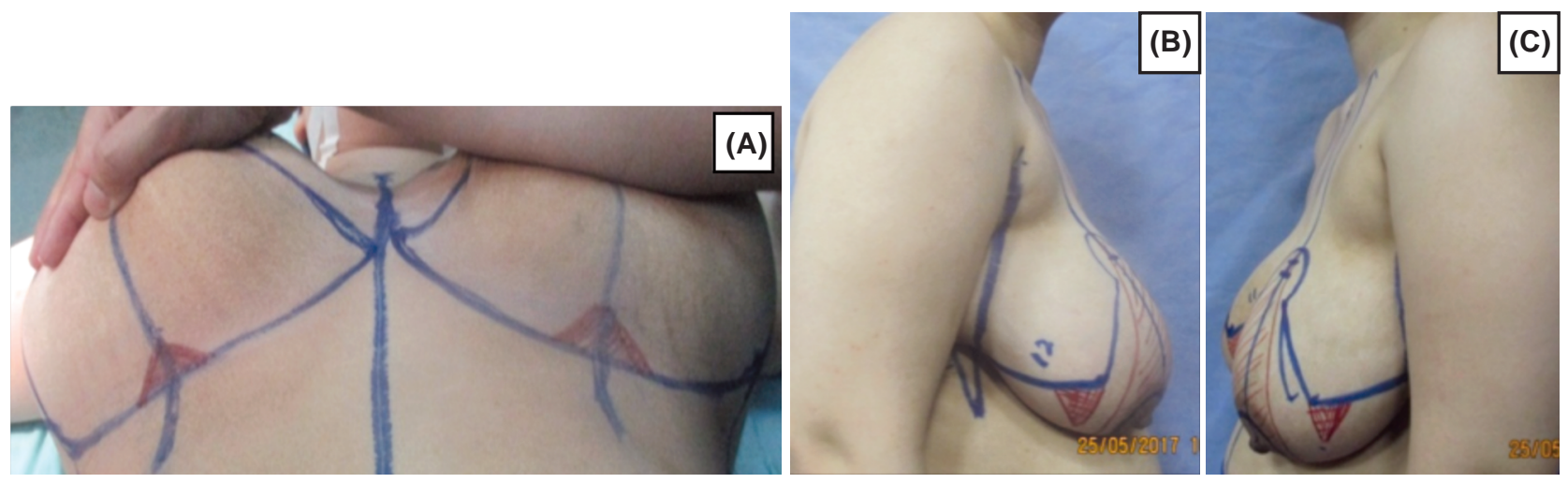

Fig. (1): (A): Marking of inverted V flap in the inframmamary fold. (B \& C): Marking of triangular lipodermal flaps.
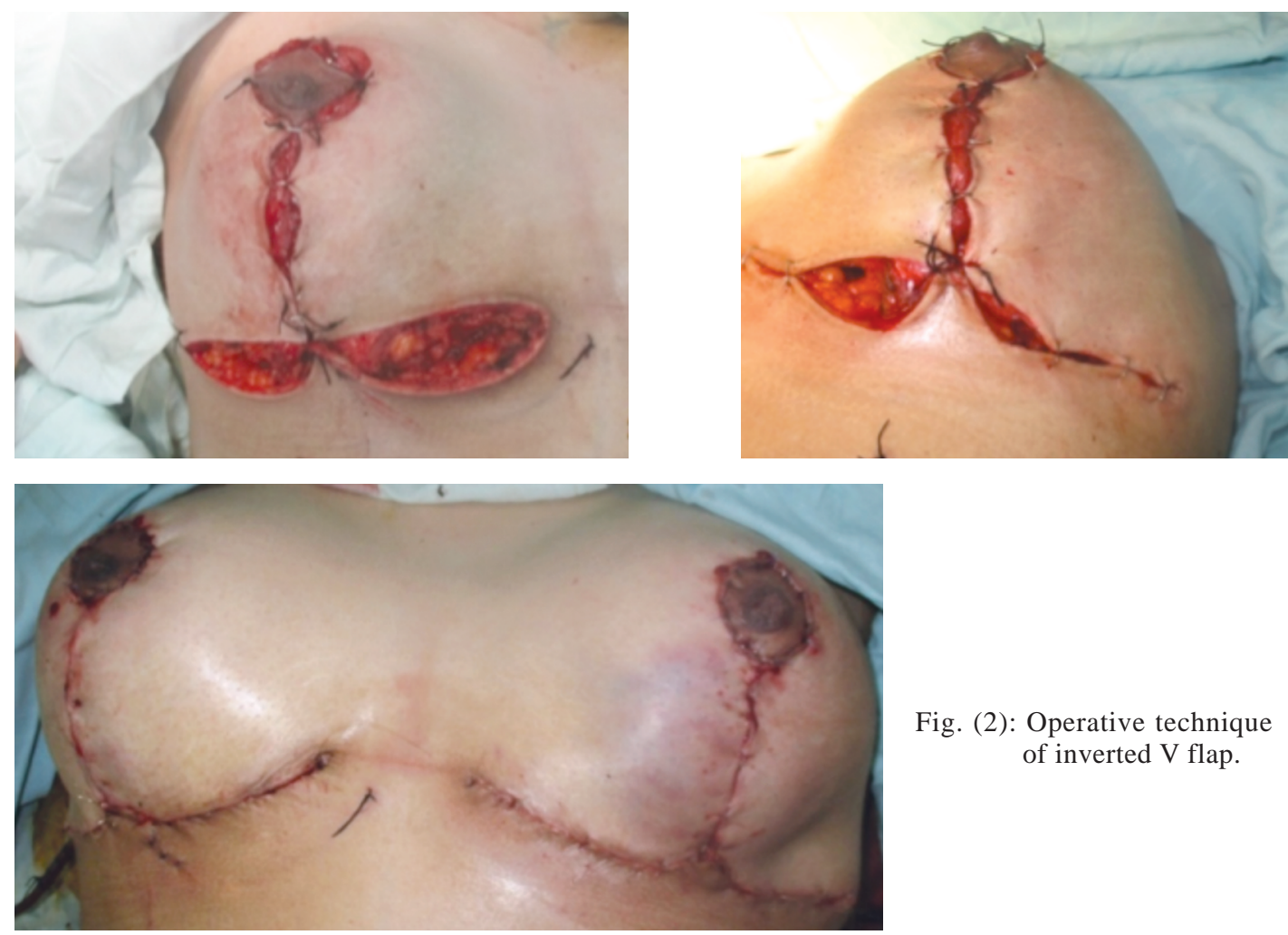

Fig. (2): Operative technique of inverted $\mathrm{V}$ flap.

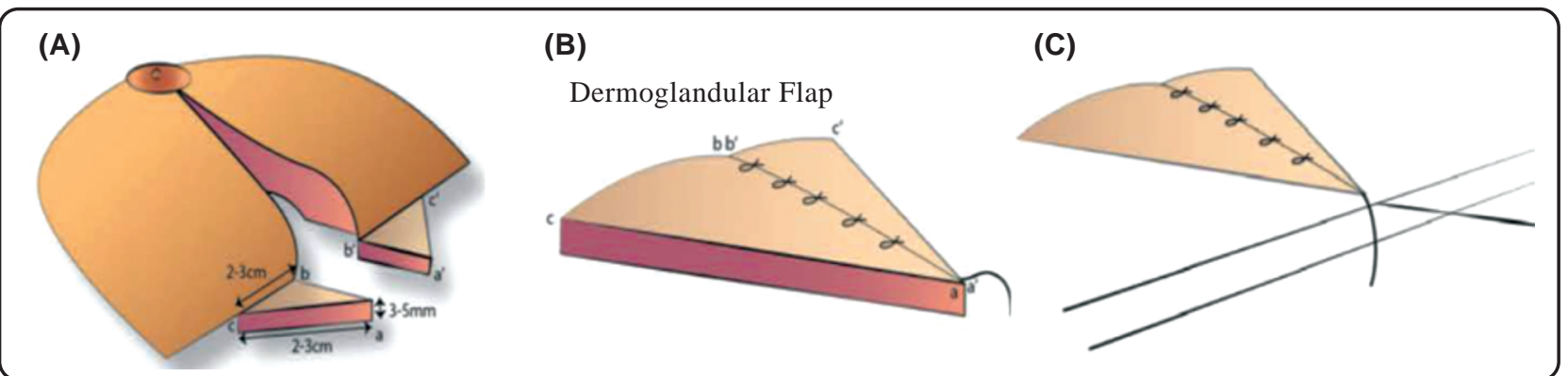

Fig. (3): Diagram showing the design of triangular lipodermal flaps [1]. 

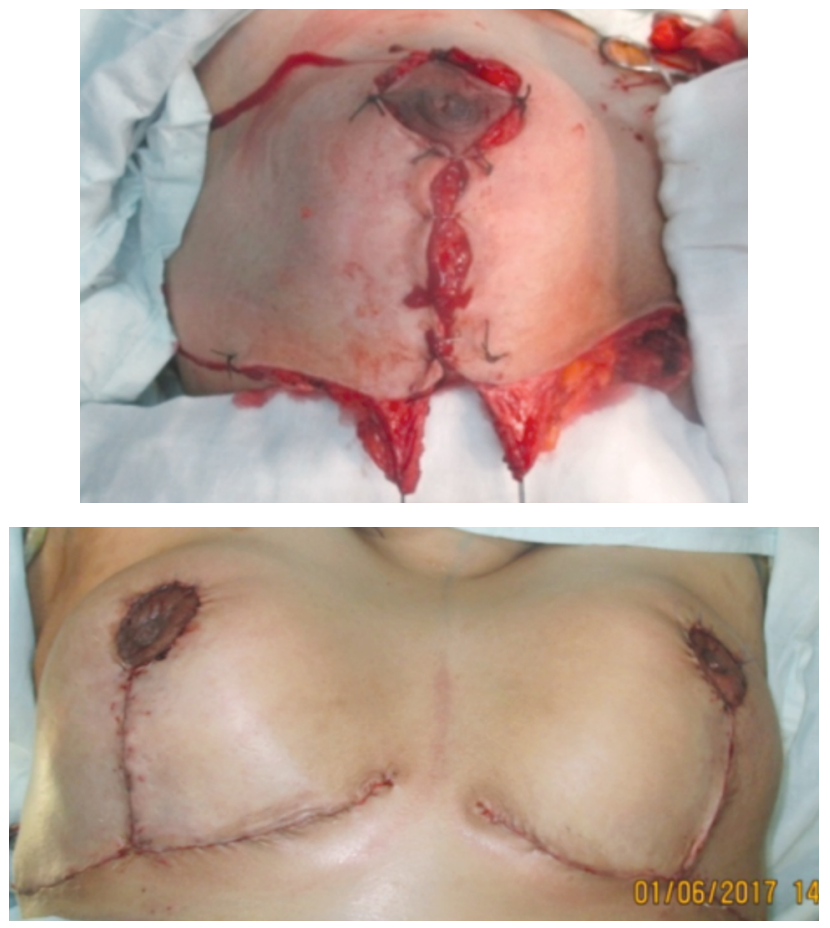

\section{Postoperative management:}

- The dressing was changed the next day and thereafter, every other day or when there was any soaking or suspicion of infection.

- Suction drains removed after 48 hours and any non-absorbable sutures removed after 14 days.

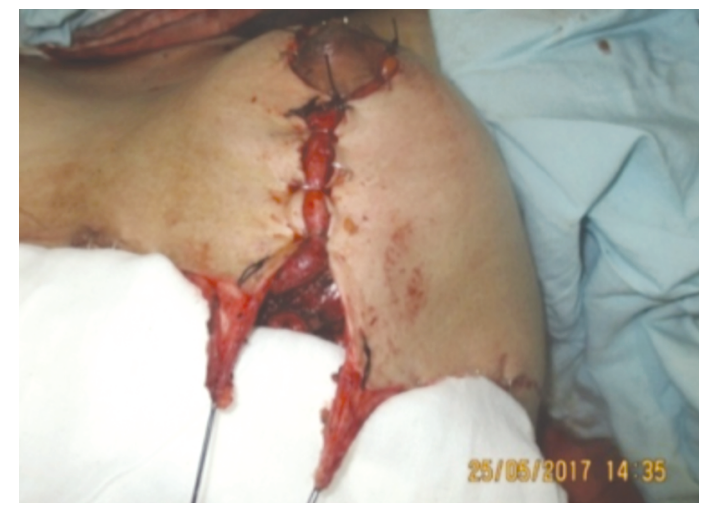

Fig. (4): Pictures showing lipodermal flap post deepithelialization after reshaping of the breast mound.

\section{Follow-up:}

Scheduled at the end of the first, second, and fourth postoperative weeks and checking the $T$ junction for occurrence of dehiscence or not and assessing the degree of dehiscence.

Patient satisfaction questionnaire then filled by direct interview with the patients (Fig. 5).

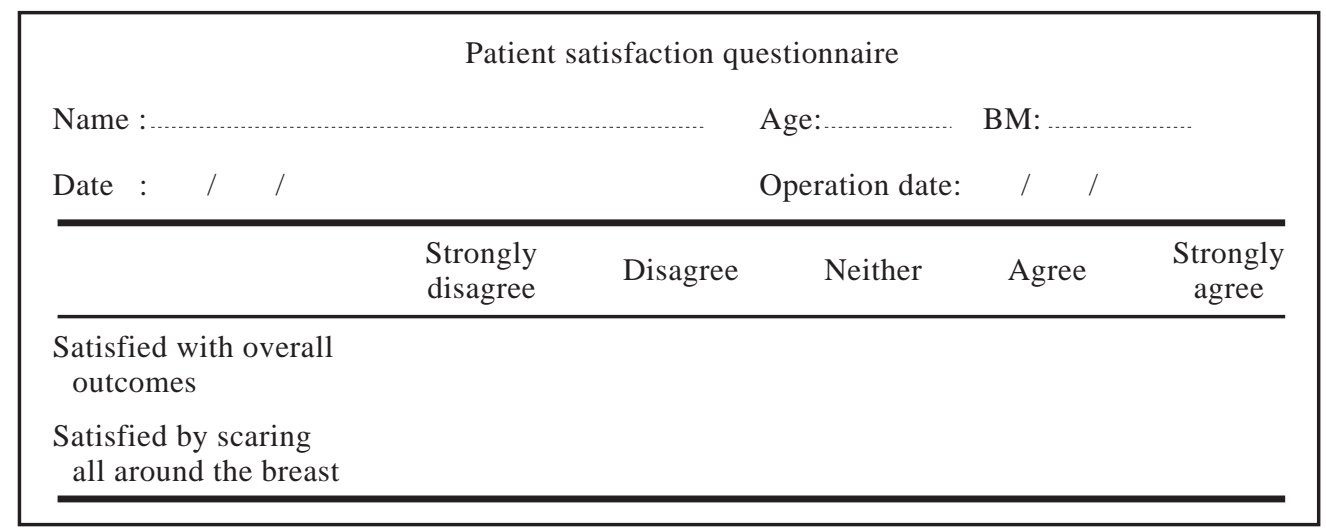

Fig. (5): Showing the patient satisfaction questionnaire.

\section{RESULTS}

In this study, 30 patients were included, which is a total of 60 breasts. Data were statistically described in terms of mean \pm standard deviation $( \pm \mathrm{SD})$, median and range, or frequencies (number of cases) and percentages when appropriate. Comparison of numerical variables between the study groups was done using Student $t$-test for independ- ent samples. For comparing categorical data, Chisquare $\left(\chi^{2}\right)$ test was performed. Exact test was used instead when the expected frequency is less than 5. $p$-values less than 0.05 was considered statistically significant.

A prospective comparison of $50 \%$ of patients who underwent Wise pattern superomedial pedicle reduction mammoplasty with the triangular lipo- 
dermal flap and the other $50 \%$, who underwent Wise pattern superomedial pedicle reduction mammoplasty with the inverted V flap, was done, regarding occurrence of dehiscence at $\mathrm{T}$ junction.

The results demonstrated no significant difference between the two groups regarding age (20 to 57 years versus 20 to 55$)(p=0.418)$, BMI (23.9 to $34.4 \mathrm{~kg} / \mathrm{m}^{2}$ versus $\left.24.6-35.5 \mathrm{~kg} / \mathrm{m}^{2}\right)(p=0.541)$ and amount of breast tissue excised (400-650gm versus $300-988 \mathrm{gm}$ from right breast) $(p=0.979)$ and $(300$ $665 \mathrm{gm}$ versus $300-900$ from the left breast) $(p=0.631)$.

The wound dehiscence is divided into major dehiscence which is defined as wound separation more than $2 \mathrm{~cm}$ and minor dehiscence which is defined as wound separation of $2 \mathrm{~cm}$ or less. Two patients $(13.3 \%)(p=0.422)$ in group $(\mathrm{A})$ have major dehiscence compared to 1 patient $(6.7 \%)(p=0.411)$ in group (B). Moreover, three patients (20\%) in group $(\mathrm{A})$ have minor dehiscence compared to one $(6.7 \%)$ patient in group (B). Both of them are statistically insignificant (Fig. 6). It has been noticed that in group (A) the two cases of major dehiscence have BMI of $34.9 \mathrm{~kg} / \mathrm{m}^{2}$ and 33.9 $9 \mathrm{~kg} / \mathrm{m}^{2}$ respectively and the case of major complication in group (B) has a BMI of $32.9 \mathrm{~kg} / \mathrm{m}^{2}$.

The patient satisfaction was measured in regard to the patient being happy with overall outcomes and the scaring, the overall satisfaction was $85.3 \%$ in group (A) compared to $93.3 \%$ in group (B). This is statistically significant $(p=0.028)$ (Table 1$)$.

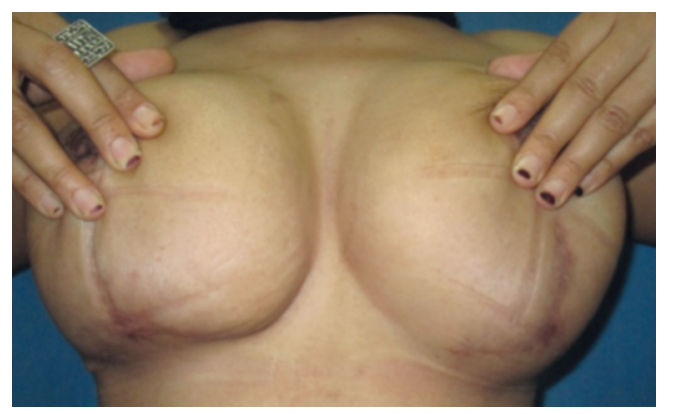

Fig. (7): Post-operative photos of some of group (A) cases.
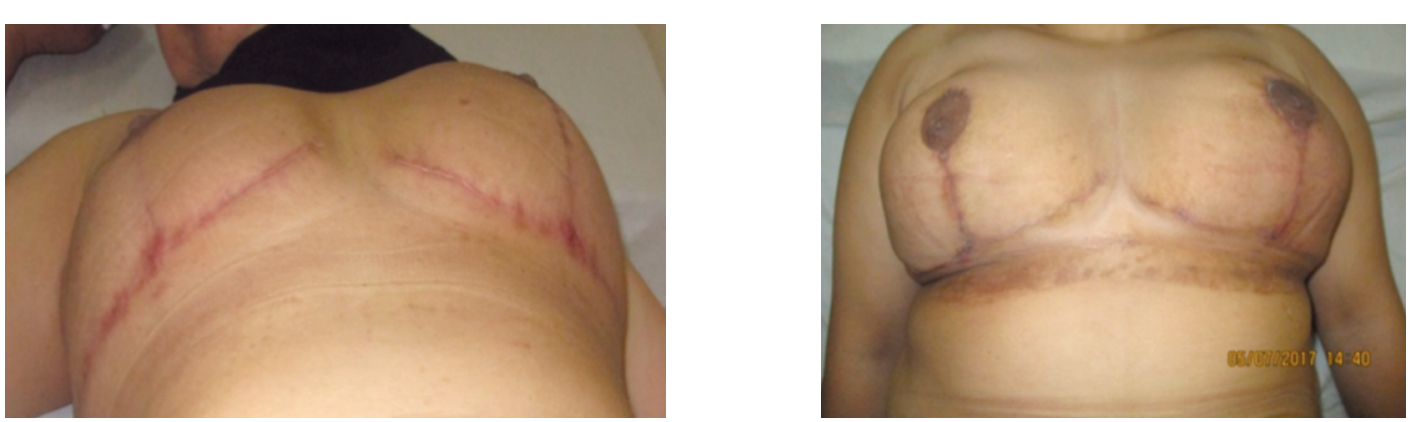

Fig. (8): Post-operative photos of some of group (B) cases.

Table (1): The incidence of T-junction wound dehiscence in both groups.

\begin{tabular}{llccc}
\hline Group & & $\begin{array}{c}\text { Major } \\
\text { dehiscence }\end{array}$ & $\begin{array}{c}\text { Minimal } \\
\text { dehiscence }\end{array}$ & $\begin{array}{c}\text { No } \\
\text { dehiscence }\end{array}$ \\
\hline Inverted V flap & $\mathrm{N}$ & 2 & 3 & 10 \\
& Ratio & $13.3 \%$ & $20 \%$ & $66.7 \%$ \\
Triangular & $\mathrm{N}$ & 1 & 1 & 13 \\
lipodermal flap & Ratio & $6.7 \%$ & $6.7 \%$ & $86.7 \%$ \\
\hline
\end{tabular}

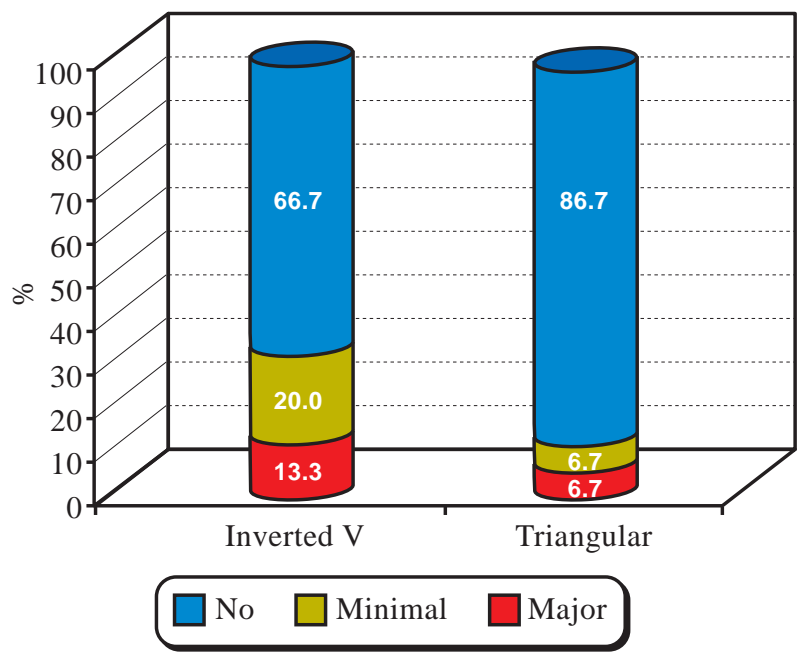

Fig. (6): Chart showing the incidence of major and minor complications in both study group.

Table (2): Showing the patient satisfaction in both groups.

\begin{tabular}{lccc}
\hline & $\begin{array}{c}\text { Inverted } \\
\text { V flap }\end{array}$ & $\begin{array}{c}\text { Triangular } \\
\text { lipodermal flap }\end{array}$ & $\begin{array}{c}p- \\
\text { value }\end{array}$ \\
\hline $\begin{array}{l}\text { Satisfied by } \\
\text { overall outcomes }\end{array}$ & $85.3 \%$ & $93.3 \%$ & 0.028 \\
\hline
\end{tabular}

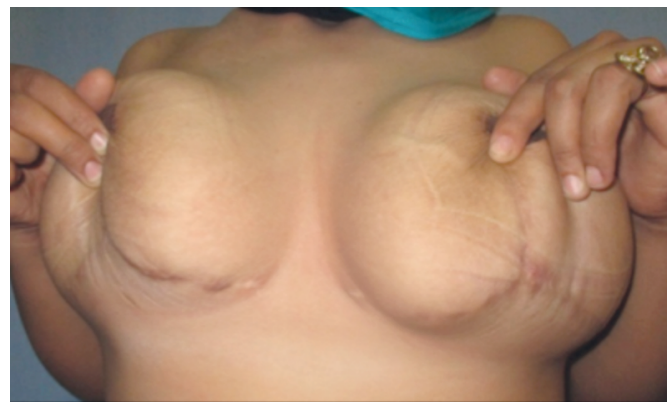

Fig. (8): Post-operative photos of some of group (B) cases. 


\section{DISCUSSION}

Despite the increased utilization of short scar mammaplasties, the Wise keyhole pattern still remains the most common skin incision used in reduction mammaplasty. It allows for flexibility in the method of nipple areola transposition and gives a predictable result.

The major disadvantage of the Wise pattern is the high scar burden. It also runs the risk of giving a boxy breast appearance if the medial and lateral incisions do not follow the natural curve of the breast [5]. Tension is the keyword in the occurrence of necrosis or hypertrophic scars, although tension helps to make breasts firmer and more youthful [6].

In 1994 small triangle has been proposed by Benmeir et al. [7] to be left in the junction of mid clavicle-areolar line and inframammary line to decrease the tension on the junction of the vertical and transverse inframammary incisions. They compared the results between two groups undergoing McKissock reduction where in the first group they have used the midline triangle and in the second group they haven't. They have found out that no necrosis has occurred in the first group while in the second group $15 \%$ of cases had necrosis or wound dehiscence at the T-junction.

Ghareeb in 2003 [6] observed that during reduction of huge breasts, the great stretch of the dermis and subcutaneous tissues affects the structure of these tissues rendering the subcutaneous fatty layer less condensed and less adherent to the skin. He used semilunar inframammary incision and observed better healing and less hypertrophic scarring. Chao et al. [8] also endorsed the V flap modification by adding of expanded inframammary fold skin triangle, and got improved outcomes in high-risk large volume breast reduction patients. A more recent study suggested the addition of inframammary fold U-shaped flap and removal of distal skin from the Wise pattern 'wings'. A major advantage of this principle is that it exchanges vulnerable skin for reliable well-vascularized tissue that has not been undermined [9]. Many other studies have introduced other modifications to Wise pattern reduction mammoplasty, like the use of cross dermal flap [10], three triangular dermal flaps [11], and the triangular lipodermal flaps at the caudal end of each breast pillars described by. Khalil et al. [1] to act also as an internal dermal sling, thus providing better wound healing and maintaining the best breast projection with the provision of optimum aesthetic results.
The present study focused on the prospective comparison between inverted $\mathrm{V}$ flap in the inframammary fold described by Chao et al. [8] in 2014 and Triangular lipodermal flaps technique described by Khalil et al., in 2016 [1] in regards to the occurrence of $\mathrm{T}$ junction dehiscence and patient satisfaction. In our current study the overall incidence of the dehiscence was $23.3 \%$ (10\% was encountered as major dehiscence and $13.3 \%$ as minimal dehiscence). We noticed that Two patients $(13.3 \%)$ in inverted V flap group have major dehiscence and three patients $(20 \%)$ have minor dehiscence compared to one patient $(6.7 \%)$ in triangular lipodermal flap group has major dehiscence, and one patient $(6.7 \%)$ has minor dehiscence. which is statistically insignificant.

Another important aspect that needs to be mentioned is that in inverted V flap group the two cases of major dehiscence have BMI of $34.9 \mathrm{~kg} / \mathrm{m}^{2}$ and $33.99 \mathrm{~kg} / \mathrm{m}^{2}$ respectively and the case of major complication in triangular lipodermal flap has a BMI of $32.9 \mathrm{~kg} / \mathrm{m}^{2}$. This points out to the influence of subcutaneous fat thickness on the incidence of wound dehiscence in high BMI patients.

Khalil et al. [1] concluded that out of 13 cases (7.5\%) who develop $\mathrm{T}$ junction dehiscence, nine occurred in patients with BMI $>28.7 \mathrm{~kg} / \mathrm{m}^{2}$ which is statistically significant. Gamboa et al. [12] stated that wound healing complications increased with increasing the BMI of the patients.

The patient satisfaction after mammoplasty is directly related to the patient perception of scar, our result revealed that the patient satisfaction by overall outcomes is $93.3 \%$ in triangular lipodermal flap compared to $85.3 \%$ in inverted V flap group which is statistically significant $(p=0.028)$. Most recent studies found that subjective and objective clinical evaluation of the patient revealed that $94 \%$ of patients graded their outcomes as highly satisfactory [1].

\section{Conclusion:}

When performing Wise pattern reduction mammoplasty, the most common complication is the dehiscence at the T-junction. Modifications to the Wise pattern technique have been previously described to offset the tension at the $\mathrm{T}$ junction. In this study, we compared two methods for prevention of $\mathrm{T}$ junction dehiscence which include inverted V flap and triangular lipodermal flap. Regarding the outcomes the rate of major and minimal wound dehiscence was lesser in triangular lipodermal flap than in inverted $\mathrm{V}$ flap though statistically insignificant. It has been noted that the wound healing 
complications increased with increased BMI of the patients.

Moreover, most of the patients are satisfied by overall outcomes with satisfaction rate of $93.3 \%$ in triangular lipodermal flap and $83.3 \%$ in inverted $\mathrm{V}$ flap. This makes the conclusion that the triangular lipodermal flap could be the future preferred technique as a modification to Wise pattern reduction mammoplasty for prevention or reduce the incidence of $\mathrm{T}$ junction complications.

\section{REFERENCES}

1- Khalil H.H., Marco M. and Geeta S.: "Triangular lipodermal flaps in Wise pattern reduction mammoplasty (superomedial pedicle): A novel technique to reduce T-junction necrosis". Plastic Surgery, 24.3: 191-194, 2016.

2- Henderson P.W., Chang M.M., Taylor E.M., et al.: The "Superior Ledge": A Modification of the Standard Superomedial Pedicle Reduction Mammoplasty to Accentuate Nipple-Areola Complex Projection. Aesthetic Plastic Surgery, 40 (5): 733-738, 2016.

3- Brown R.H., Siy R., Khan K. and Izaddoost S.: The Superomedial Pedicle Wise-Pattern Breast Reduction: Reproducible, Reliable, and Resilient. In Seminars in Plastic Surgery (Vol. 29, No. 02, pp. 094-101). Thieme Medical Publishers, 2015.

4- Orlando J.C. and Guthrie R.H. Jr.: The superomedial dermal pedicle for nipple transposition. Br. J. Plast. Surg., 28: 42-45, 1975.
5- Hidalgo D.A.: Improving safety and aesthetic results in inverted T scar breast reduction. Plast. Reconstr. Surg., 103: 874-886; discussion 887-889, 1999.

6- Ghareeb F.M.: The Inframammary Semilunar Incision in Reduction Mammaplasty. Egypt J. Plast. Reconstr. Surg., Vol. 27, No. 2: 281-285, 2003.

7- Benmeir P., Lausthaus S., Neuman A., et al.: The inframammary midline triangle in reduction mammaplasty: The renewal of an old idea. Plast. Reconstr. Surg., 93: 413, 1994.

8- Chao J.W., Taylor E.M. and Rohde C.H.: Reducing wound healing complications of Wise pattern breast reduction with the inverted "V" modification. J. Plast. Reconstr. Aesthet. Surg., 67 (3): 421-422, 2014.

9- Summerhayes C., Cutress R.I. and Hurren J.S.: Modification of the Wise Pattern Breast Reduction for Therapeutic Mammoplasty. In Aesthetic Surgery of the Breast (pp: 949-953). Springer Berlin Heidelberg, 2015.

10- De la Plaza R., De la Cruz L., Moreno C. and Soto L.: The crossed dermal flaps technique for breast reduction. Aesthetic Plastic Surgery, 28 (6): 383-392, 2004.

11- Domergue S., Ziade M., Lefevre M., Prud'homme A. and Yachouh J.: Dermal flaps in breast reduction: prospective study in 100 breasts. Journal of Plastic, Reconstructive \& Aesthetic Surgery, 67 (6): e147-e150, 2014.

12- Gamboa-Bobadilla G.M. and Killingsworth C.: Largevolume reduction mammaplasty: The effect of body mass index on postoperative complications. Annals of Plastic Surgery, 58 (3): 246-249, 2007. 